\title{
Polyarteritis presenting with thrombocytosis and palliated by plasma exchange
}

\author{
TERRY HAMBLIN \\ M.B., Ch.B., M.R.C.P. (UK), M.R.C.Path.
}

\author{
DAVID OSCIER \\ M.A., M.B., B.Chir., M.R.C.P. (UK)
}

Department of Haematology, Royal Victoria Hospital, Bournemouth

\begin{abstract}
Summary
A 66-year-old patient with polyarteritis nodosa presented with thrombocytosis and was found to have circulating immune complexes. Treatment by plasma exchange produced symptomatic improvement and lowered both the platelet count and the level of immune complexes. While plasma exchange is a useful technique in investigating the pathogenesis of the disease, predisolone is a more convenient way of treating it.
\end{abstract}

\section{Introduction}

The factors leading to the raised platelet count in the various disorders associated with reactive thrombocytosis are almost totally obscure (Wintrobe, 1974). A case is here reported in which the response to plasma exchange gives a clue to the pathogenesis of the condition.

\section{Case report}

A 66-year-old housewife complained of weightloss and of pain and weakness in her arms and legs. Her pain was worse on wakening and all her muscles were affected. She had no arthritis. She also complained of discomfort on swallowing and numbness in her right hand.

On examination she was pale and lethargic, and had oral and vaginal candidiasis. Muscular power was reduced, especially in triceps and quadriceps, and there was impaired sensation in her right hand in the distribution of the median nerve. Vibration sense was absent in the feet and she had no ankle jerks. Liver and spleen were not enlarged.

\section{Investigations}

Hb $10.8 \mathrm{~g} / \mathrm{dl} ; \mathrm{MCV} 79 \mathrm{fl} ;$ WBC $19 \cdot 2 \times 10^{9} / 1$; neutrophils $85 \%$; lymphocytes $11 \%$; monocytes $1 \%$; eosinophils $3 \%$; platelets $1 \cdot 105 \times 10 \% / 1$; ESR $86 \mathrm{~mm}$ in the 1st hour. Blood film confirmed the thrombocytosis, and the red cells showed marked anisocytosis with burr cells. The granulocytes were left-shifted and both they and the platelets were vacuolated. Leucocyte alkaline phosphatase score was normal. Urea and electrolytes and uric acid were normal, and there was no evidence of diabetes mellitus. Serum albumin was $21 \mathrm{~g} / 1$, serum alkaline phosphatase 152 i.u./l, and creatine kinase 20 i.u./l. Protein electrophoresis confirmed the low albumin and showed raised $\alpha_{1}$ and $\alpha_{2}$ globulins. Immunoglobulins were normal. Neither hepatitis-associated antigen nor antibody were detected. ECG and chest $\mathrm{X}$-rays were normal. No features of rheumatoid arthritis were present in the X-ray of her hands and no auto-antibodies could be detected. DNA binding was $5.7 \%$ by the tritiated actinomycin $\mathrm{D}$ method (normal) (Young, 1976).

Bone marrow showed hypercellularity of all cell lines and plentiful iron stores. Urine culture grew Escherichia coli. Deltoid muscle biopsy was diagnostic of polyartertis nodosa.

It took 3 weeks to establish the diagnosis during which time the $\mathrm{Hb}$ fell to $7 \cdot 2 \mathrm{~g} / \mathrm{dl}$. Her leucocytosis and thrombocytosis were unchanged, but her general condition deteriorated. She needed regular analgesics for her muscle pain, her candidiasis did not improve on specific treatment and her lethargy became worse. No evidence of respiratory or renal involvement was found.

Tests for circulating immune complexes

(a) Anti-complementary activity was absent.

(b) The platelet aggregation test of Penttinen and Mylla (1968) was positive to a titre of $1: 8$.

(c) The Clq 'sticky tube' test of Hay, Nineham and Roitt (1976) bound 101.8 ng of antibody. In this test, Clq is bound to polystyrene tubes. Putative immune complexes in the test serum will bind to the Clq and may be detected by radio-labelled anti-IgG.

\section{Treatment}

She was treated with three 2-litre plasma exchanges on successive days using the Haemonetics 30 Cell Separator. There was an immediate clinical improvement, her muscle pains disappearing after the first plasma exchange. Her candidiasis disappeared, her weakness improved, her platelet count fell to $625 \times 10^{9} / 1$ (Fig. 1) and her ESR to 12 . The level of circulating immune complexes (Fig. 2) and the 


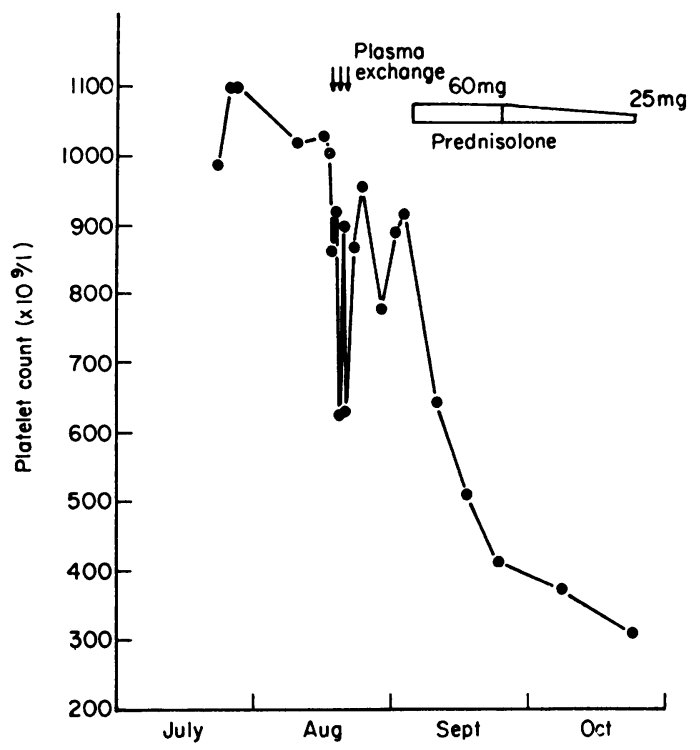

Fig. 1. Response of platelet count to treatment.

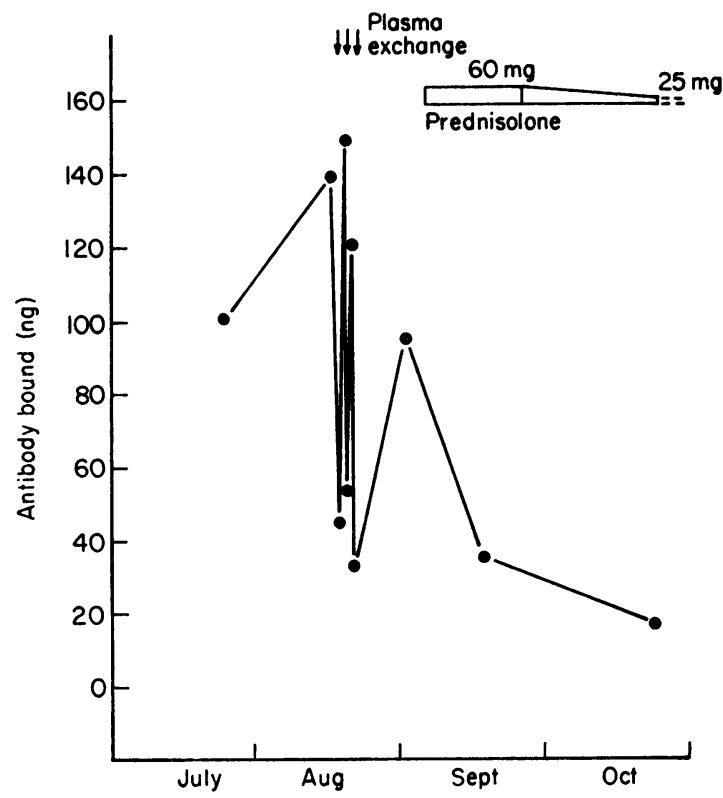

FIG. 2. Response to treatment of level of circulating immune complexes measured by $\mathrm{Clq}$ binding.

white count also fell. Two weeks after the third plasma exchange she relapsed with a return of her weakness, candidiasis and thrombocytosis and in addition she developed a left-sided foot drop. She was started on prednisolone $60 \mathrm{mg} /$ day and showed an immediate and equally dramatic improvement. Her platelet count returned to normal and 5 months later she is completely well apart from minor residual neuropathy. Her weight has increased by $12.7 \mathrm{~kg}$ and she remains on prednisolone $7.5 \mathrm{mg} / \mathrm{day}$.

\section{Discussion}

Polyarteritis nodosa is a multi-system disorder caused by the circulation of immune complexes and their deposition in small blood vessels, leading to inflammatory changes and fibrinoid necrosis in their walls. In some cases the antigenic component of the complex has been recognized as hepatitis B antigen (Gocke, Hsu and Morgan, 1970). Thrombocytosis has not previously been noted as a feature of polyarteritis nodosa but in other diseases where immune complexes have been implicated thrombocytosis is not uncommon, e.g. rheumatoid arthritis, Wegener's granulomatosis and inflammatory bowel disease (Bean, 1964; Marchasin, Wallerstein and Aggeler, 1964).

The cause of the thrombocytosis is unknown. The normal destruction of effete platelets is by the reticulo-endothelial system (RES) and it has been suggested that interference with its function prolongs platelet life span (Abildgaard and Simone 1967). Circulating immune complexes are known to be able to saturate the RES and abrogate its activityo (Haakenstad and Mannik, 1974). Both polymorph (Bowers, Craddock and Jacob, 1977) and platelets? (Mustard and Packham, 1968) may phagocytose immune complexes and this may impair their function.

That this patient was suffering from the effects of reticulo-endothelial blockade is suggested by her candidiasis in the presence of a polymorph leucocytosis, and also by the vacuolation of both platelets and polymorphs. Verrier Jones et al. (1976) suggested that the beneficial effect of plasma exchange in systemic lupus erythematosus was due to the unblocking of the reticulo-endothelial system by the removal of immune complexes. Lockwood et al. (1977) have also shown that plasma exchange is an efficient way of removing immune complexes.

The fall in platelet count, white count, and the level of immune complexes, together with the clinical improvement and disappearance of the candidiasis following plasma exchange in this patient all support the view of the pathogenesis of her disease. Furthermore, the relapse of all these features on stopping the treatment is additional evidence in support of this hypothesis.

Finally, it should be noted that although polyarteritis nodosa is one further disease in which plasma exchange may be beneficial, the response to corticosteroids which are both cheaper and more easily applied, was equally dramatic. 


\section{Acknowledgments}

Terry Hamblin acknowledges a grant from the Wessex Oncology Fund to run the Cell Separator and support from the Wessex Regional Research Fund to measure immune complexes.

\section{References}

AbildgaARd, C.F. \& Simone, J.V. (1967) Thombopoiesis. Seminars in Haematology, 4, 424.

B\&AN, R.H.D. (1964) Thrombocytosis in auto-immune disease. Proceedings of the 10th International Congress of Blood Transfusion, Stockholm, p. 43.

Bowers, T.K., CRaddock, P.R. \& JaCoB, H.S. (1977) Acquired granulocyte abnormality during drug allergic reactions: possible role of complement activation. Blood, 49, 3.

Gocke, D.J., Hsu, K. \& Morgan, G. Lockshin, M., Bombardieri, S. \& Christian, C.L. (1970) Association between polyarteritis and Australia antigen. Lancet, ii, 1149.

HaAkenstad, A.I. \& Mannik, M. (1974) Saturation of the reticuloendothelial system with soluble immune complexes. Journal of Immunology, 112, 1939.

HaY, F.C., Nineman, L.J. \& RoItT, I.M. (1976) Routine assay for the detection of immune complexes of known immunoglobulin class using solid phase Clq. Clinical and Experimental Immunology, 24, 396.

Lockwood, C.M., Rees, A.J., Pinching, A.J., Pussel, B., Sweny, P., Uff, J. \& Peters, D.K. (1977) Plasma-exchange and immunosuppression in the treatment of fulminating immune-complex crescenteric nephritis. Lancet, i, 63.

Marchasin, S., Wallerstein, R.I. \& Aggeler, P.M. (1964) Variations of the platelet count in disease. California Medicine, 101, 95.

Mustard, J.F. \& PaCkham, M.A. (1968) Platelet Phagocytosis. Series Haematologica (Book stall title), 1, 168.

Penttinen, K. \& Mylla, G. (1968) Interaction in human blood platelets, viruses and antibodies. Part I. Platelet aggregation test with micro equipment. Annales medicinae experimentalis et biologiae Fenniae, 46, 188.

Verrier Jones, J., Bucknall, R.C., Cumming, R.H., Asplin, C.M., Fraser, I.D., Bothamley, J., Davis, P. \& HaMblin, T.J. (1976) Plasmapheresis in the management of acute systemic erythematosus. Lancet, i, 709.

Wintrobe, M.M. (Editor) (1974) Clinical Haemotology, p. 1102. Lea \& Febiger, Philadelphia.

YounG, B.J. (1976) Detection of antibodies to DNA studies using tritiated actinomycin D-labelled DNA. Journal of Medical Laboratory Science, 33, 167. 